\section{The WTO's balancing act}

\author{
Kristine Novak \\ Nature Reviews Cancer, San Francisco, California, USA \\ E-mail:k.novak@naturesf.com.
}

\begin{abstract}
The 146 member nations of the World Trade Organization recently came to an agreement that will allow poor nations to avoid patent restrictions and import generic versions of urgently needed medicines, but this accord has been met with criticism from international aid organizations. What effects will this agreement have on reducing the burden of disease in the developing world, and also on the pharmaceutical industry?
\end{abstract}

J. Clin. Invest. 112:1269-1273 (2003). doi:10.1172/JCI200320177.

According to estimates from the United Nations AIDS group, 38.6 million adults were living with HIV/AIDS worldwide at the end of 2002, an estimated 29.4 million in sub-Saharan Africa (Figure 1). Each day, thousands of people in developing nations also die from other infectious diseases, such as malaria and tuberculosis (Figure 2). Although medicines are available to treat or cure these ailments, they do not reach most of the developing nations that have been hit hardest by these diseases. The World Trade Organization (WTO) has recently taken measures to make drugs more accessible by relaxing patent restrictions, allowing low-cost producers to export generic versions of brand-name medicines to poor nations. After almost two years of debate, members of the WTO have come to an agreement that aims to strike a balance between the needs of the suffering people and the needs of the pharmaceutical industry. But in the end, are patents really the major obstacle to treatment?

\section{WTO intellectual property rules}

A United Nations AIDS study reported that the number of people in poor

Address correspondence to: Kristine Novak, 225 Bush Street, Suite 1453, San Francisco, California, USA.

E-mail:k.novak@naturesf.com.

Conflict of interest: The author has declared that no conflict of interest exists. countries who have access to antiretroviral drugs remains extremely low: only 30,000 received medication in 2002, out of an estimated 5 million in need. On August 30, WTO member nations broke a deadlock over intellectual property protection and agreed on legal changes that make it easier for poor countries to import cheap generic drugs, if they are unable to manufacture the medicines themselves. Supachai Panitchpakdi, director-general of the WTO, called this compromise a historic agreement that would "allow poorer countries to make full use of the flexibilities of the WTO's intellectual property rules to deal with the diseases that ravage their people."

This agreement altered the WTO's Trade-Related Aspects of Intellectual Property Rights (TRIPS) agreement the intellectual property rules for the multilateral trading system (see The WTO's TRIPS agreement). In the original TRIPS document, countries could be issued "compulsory licenses" to produce drugs that are excluded from patent restrictions, to "protect human, animal or plant life or health." However, the TRIPS agreement also stated that these drugs could only be produced for a domestic market. So countries without their own pharmaceutical industry might not be able to import cheaper generics from countries such as India and Brazil, which produce lowcost generic versions of several patented AIDS drugs.

A discussion of ways to overcome this obstacle began at a WTO meeting in Doha, Qatar in November 2001. WTO ministers recognized that countries with insufficient or no pharmaceuticalmanufacturing capacities could face difficulties in making effective use of compulsory licensing, and they instructed the Council for TRIPS to find an expeditious solution to this problem before the end of 2002. WTO member nations, however, were unable to agree upon the terms under which poor countries could import generic drugs.

Progress on easing generic-drug importation restrictions was held back primarily by the US, which, under pressure from a strong pharmaceutical lobby, expressed concern about the ability of generics producers to export drugs that the pharmaceutical companies had spent millions of dollars to develop. Sale of AIDS drugs in developed countries is a multimillion-dollar industry for companies such as Abbott Laboratories, Merck and Co., and Roche Holding AG.

US representatives to the WTO requested limits on the situations in which compulsory licenses could be issued, demanding that patent deregulation be restricted to specific diseases and limited to certain countries. WTO representatives from poor countries, in contrast, strongly objected to restrictions on the kinds of medicines that would be available. The US also wanted the TRIPS plan to include smuggling safeguards, to prevent low-cost, generic versions of medicines from being resold in developed nations. Debates over these issues held up the final TRIPS plan for almost two years.

\section{A WTO agreement}

A compromise was finally reached at the August 30 meeting of the WTO in Geneva. A final version of the WTO's intellectual property rights laws was 


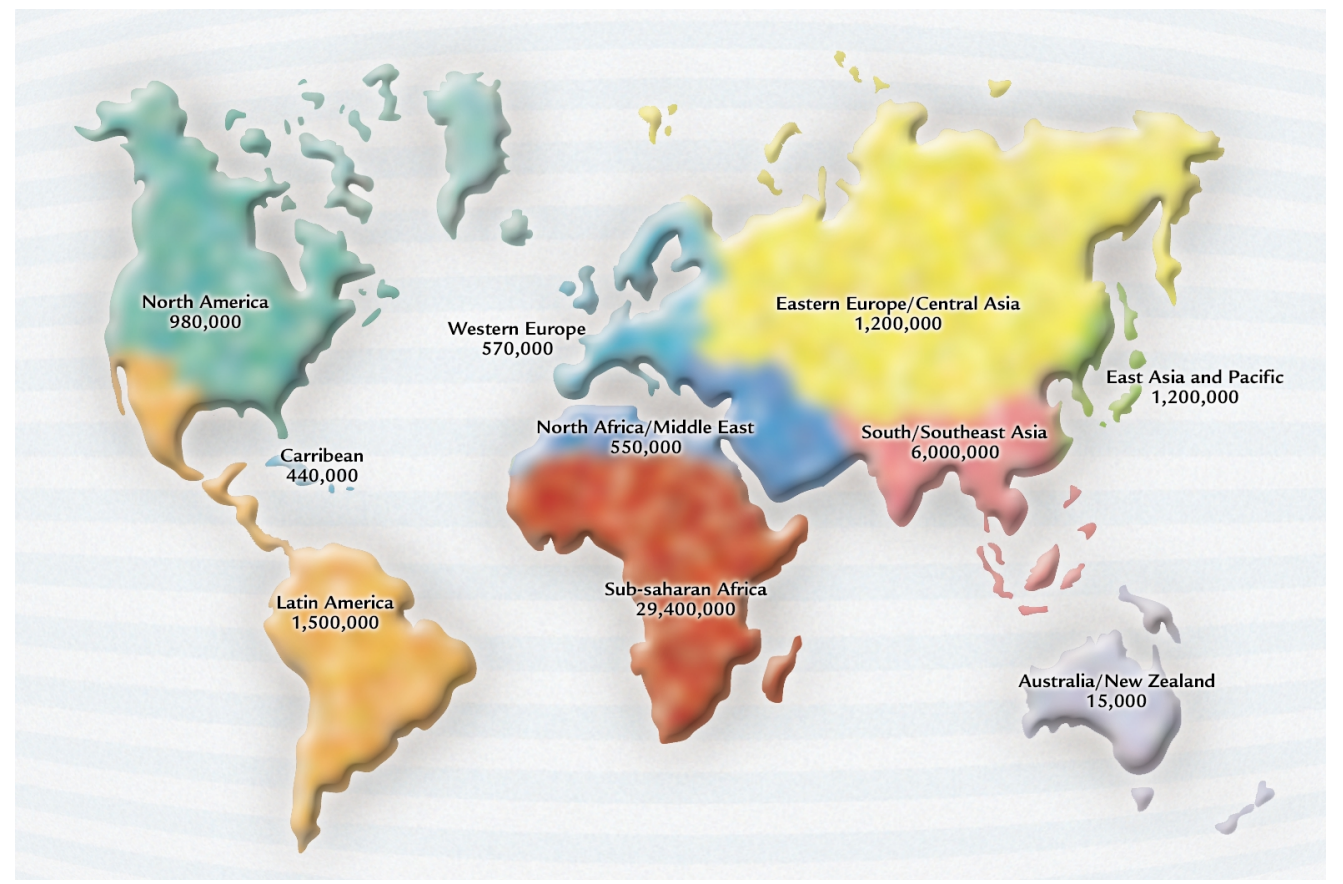

\section{Figure 1}

People estimated to be living with HIV/AIDS as of the end of 2002. Source: World Health Organization. approved by all 146 members of the organization (including 53 developing countries) after an impassioned plea by representatives from African nations to stop the bickering over details and to move the legislation forward. Under the latest provisions, the overriding of patents and the importation of generic drugs must be undertaken by a country only "in good faith to protect public health" and must "not be an instrument to pursue industrial or commercial policy objectives." The new agreement also calls for special packaging or differently colored tablets to be used for generics, to prevent their resale in wealthy nations.

Under the latest WTO rules, developed countries have agreed not to make use of compulsory licensing, and the richest developing nations, including Israel, Hong Kong, Mexico, and South Korea, as well as Taiwan, would only use the measure in situations of national emergency. The US also dropped its restrictions on the types of drugs that can be imported; the final plan supports importation of compulsory-licensed drugs for all diseases. Faizel Ismail, South Africa's WTO representative, stated that "this decision is extremely important for many African countries who need to be able to import generic drugs which are affordable, and who don't have the capacity to produce them.”

\section{The limitations of TRIPS}

However, not everyone is happy with the deal. The Kenyan medical lobby warned that the deal would hinder the development of the pharmaceutical industry in its own nation.

Kenya has a significant pharmaceutical industry, and, like other WTO members with pharmaceutical capabilities, Kenya would also be restricted in its ability to export generic pharmaceuticals - it would be able to sell them only to countries that have declared a national emergency. "Wealthy countries do not have to declare national emergencies to make use of TRIPS safeguards, so why should Kenya and other developing countries have to do so?" said Oduor Ong'wen (EcoNews Africa). "Will African countries have to declare tuberculosis or malaria a national emergency in order to get affordable drugs?”

Kenya Coalition for Access to Essential Medicines spokeswoman Beryl Leach stated that the Geneva agreement would make it difficult for developing nations to promote their own pharmaceutical industries and manufacture generic drugs. "The deal was a bad one, forced on developing countries by the United States, European Union and other powerful WTO members," Leach said, adding that the agreement was "unworkable and impractical at its best." "Those who are expecting drugs to start flowing will be in for a rude shock and disappointment," she warned.

International humanitarian organizations also expressed doubt that the agreement could deliver any relief. In a joint statement, Oxfam and Médecins Sans Frontières (MSF) said that the "WTO agreement that is ostensibly intended to get drugs to the poorest countries does not provide a workable solution." MSF, which won the 1999 Nobel Peace Prize for its global work in emergency medical assistance, was the first to attack world trade rules on drug patents, which, it says, raise prices and restrict access to vital medicines. The agency claims that the TRIPS agreement is a burdensome system that does nothing to ensure that generic production will happen. Rather, the agreement imposes new "legal, economic and political obstacles to ensuring production and export of generic medicines in the future."

"Two compulsory licenses will have to be issued under the TRIPS agreement - one for the exporting country, and one for the importing country," said Ellen T'Hoen, MSF's coordinator for policy and advocacy. "Exporting countries will also have to report to the 

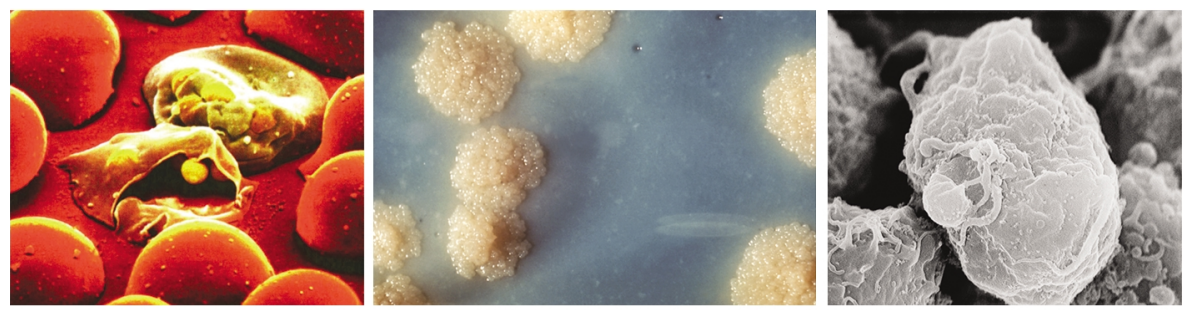

Figure 2

Can cheap drugs fight malaria, tuberculosis, and HIV infections? Images provided by Centers for Disease Control (Plasmodium falciparum in erythrocytes, CDC; Tuberculosis colonies, George Kubica; HIV infecting lymphocyte, C. Goldsmith).

WTO when they issue a license, and at this stage they will come under pressure from countries with big pharmaceutical industries not to do so." In June 2000, Brazil's pharmaceutical industry came under legal attack from the US for violating patent rights and producing generic copies of antiretroviral drugs to treat Brazilian AIDS patients. The US, however, dropped its complaint, announcing that it preferred "to resolve trade disputes by seeking constructive solutions."

Jonathan Berger, a South African researcher at the AIDS Law Project, based at the University of the Witwatersrand in Johannesburg, says the Geneva deal also leaves poor importing countries, which could not make their own drugs, at the mercy of richer exporting countries. "The problem is that even when a country which desperately needs the drugs issues a compulsory license to import them, it is up to the exporting country to do the same," he said in a public statement. "In many countries with a capability to manufacture generic drugs and export them, their patent laws may not provide for export of products under compulsory licenses, or may not allow for such licenses to be issued, or the political will may not exist."

Not so, says Harvey Bale, directorgeneral of the International Federation of Pharmaceutical Manufacturers Associations. "This agreement has no red tape - no country is required to seek prior approval from the WTO before importing generic drugs. Any country that wants to make use of the agreement can go ahead and do so." Bale believes that many activists are condemning the agreement because they would like to see all drug patents completely removed and are demanding that the TRIPS structure be completely abolished. "The trick is to strike a balance between the needs of devel- oping countries and of pharmaceutical companies," said Bale.

Although relaxing of patent laws can make it easier for everyone to have access to medicines, it also removes incentives from pharmaceutical companies to develop new drugs. Drugs take more than a decade to bring to market, and patents allow pharmaceutical companies to recoup research and development costs, as well as to begin developing new drugs. According to Pharmaprojects, a drug research and development database, the number of new AIDS drugs in development has declined steeply: the number of antiretroviral compounds that companies were studying fell from 250 in 1998 to 173 in 2001 . This may be due to the pressure on companies to give these drugs away for free or at cost, and to relinquish patent rights.

Bale states, however, that the current WTO agreement won't even have much of an effect on the pharmaceutical industry. "There are 21 AIDS drugs on the market that will all lose their patents eventually. Companies already offer AIDS drugs such as Nevirapine for free in over 40 countries." Since July 2000, Boehringer Ingelheim has been providing its antiretroviral drug Viramune free of charge to developing countries to prevent mother-to-child transmission of HIV-1. According to Bale, "Africa makes up only $1 \%$ of global drug sales. Companies are able, through sales they make in developed countries, to offset the cost of donating drugs to poor countries." The agreement has also made it easier for middle-income countries to produce generic drugs.

\section{The real winners?}

Many experts believe that the agreement could be a boon to the pharmaceutical industries in India, Brazil, South Africa, and other countries with drug-manufacturing capabilities, which now can produce drugs patented by the US and other pharmaceutical companies - as long as they export them only to needy nations. Yusuf K. Hamied, chairman of the Indian pharmaceutical company Cipla Ltd., told Bloomberg News, "What the agreement means to us is that we can export anti-AIDS drugs to Africa, which we weren't able to do because of the patent laws. We are right now gearing up to supply anti-retrovirals to these countries." South African pharmaceutical companies such as Aspen Pharmacare will also take advantage of the opportunity to produce generic AIDS drugs for its own country, as well as the rest of the region.

Brazil has been one of the first countries to take advantage of the TRIPS agreement. With a net worth of $\$ 8$ billion, Brazil is the eighth largest pharmaceutical market in the world. It also has one of the most successful antiAIDS programs in the world and has cut its AIDS death rate in half by providing patented antiretroviral drugs to 150,000 people free of charge. It has done this by producing generic versions of the drugs - or by getting a discount on the drugs from pharmaceutical companies by threatening to make them itself. About 143,000 Brazilians have AIDS, and antiretroviral treatment costs Brazil about \$2,000 a year per patient, compared with the $\$ 12,000$ it costs per patient in the US.

The Brazilian government has recently threatened to either import or produce their own generic versions of additional patented AIDS drugs that they say they can no longer afford to buy from multinational pharmaceutical companies. Brazil currently produces seven of the 14 drugs it distributes, but the cost of three of the patented drugs it doesn't produce lopinavir, nelfinavir, and efavirenz - 


\section{The WTO's TRIPS agreement}

The WTO's TRIPS agreement is an attempt to narrow the gaps in the protection of intellectual property rights around the world, and to bring them under common international rules. It establishes minimum levels of protection that each government must give to the intellectual property of fellow WTO members. In doing so, it strikes a balance between the long-term benefits and the possible shortterm costs to society. Society benefits in the long term when intellectual property protection encourages creation and invention, especially when the period of protection expires and the creations and inventions enter the public domain. Governments are allowed to reduce any short-term costs through various exceptions, for example, in order to tackle public health problems. And for when trade disputes arise over intellectual property rights, the WTO's dispute-settlement system is now available.

The agreement covers five broad issues:

1. How basic principles of the trading system and of other international intellectual property agreements should be applied

2. How to give adequate protection to intellectual property rights

3. How countries should enforce those rights in their own territories

4. How to settle disputes on intellectual property between members of the WTO

5. Special transitional arrangements during the period when the new system is being introduced

The complete document is available at the WTO website: http://www.wto.org/english/docs_e/legal_e/27-trips_01_e.htm.

accounts for $63 \%$ of its $\$ 200$ million annual budget for AIDS drugs. Critics have warned that this challenge could provoke retaliation by the US or drug companies, but MSF representatives commended Brazil on taking the lead to ensure access to drugs, and to implement the WTO plan.

\section{Other obstacles}

Although the WTO TRIPS agreement claims to remove legal obstacles that keep medicines from people in developing nations, the mechanisms for providing low-cost drugs to the poorest countries remain an unsolved problem. Many people cannot even afford generic drugs. MSF said the average cost of the cheapest generic antiretroviral is around $\$ 300$ per year. In most African countries, more than half the population lives on less than a dollar a day.

And even when medicines are available for free, there are serious infrastructure and distribution impediments. "The goal of the latest WTO agreement was to completely get rid of any potential legal barriers to medical treatment," said Bale. "But patent restrictions are only about $2 \%$ of the problem of delivering drugs to people in developing countries." In fact, since most countries in sub-Saharan Africa do not police or protect patent laws, many companies do not even bother to file for patent protection there.

Amir Attaran and Lee GillespieWhite have reported in JAMA a study of the patent statuses of 15 antiretroviral drugs in 53 African countries (1).
They found that antiretroviral drugs were patented in only a few African countries, and that in countries where antiretroviral drug patents existed, only a small subset of the drugs was patented. One exception was South Africa, where 13 of the 15 drugs included in the study were patented. The observed scarcity of patents was not explained simply by a lack of patent laws, since most African countries offered patent protection for pharmaceuticals for many years. Furthermore, geographic patent coverage did not appear to correlate with the number of people receiving antiretroviral treatment in Africa, indicating that patents and patent law are not, in themselves, a major barrier to treatment access.

\section{So if legal obstacles are not keeping drugs from the world's poor, what is?}

Bale cites a lack of infrastructure, doctors and nurses, diagnostics, clean water, and food, as well as political corruption, as factors that prevent access of the majority of the world's sick people to treatment. Third-world politicians often blame patent restrictions to avoid criticism for their own inability to take care of their own people, and for their own squandering of resources. According to Bale, "drugs for malaria, diarrhea diseases, and tuberculosis aren't even patented, yet many people in developing countries still don't have access to them."

But MSF believes that once drug prices are driven down, the infrastruc- ture for drug delivery will follow. MSF has established antiretroviral drug programs in Africa, Asia, Eastern Europe, and Central America to study the best, and most affordable, way to provide treatment to people carrying HIV. In a report contracted by the $\mathrm{WHO}$ and released at the 13th International Conference on AIDS and Sexually Transmitted Infections in Africa last September, the MSF reported that in the ten countries in which generic drugs were used to treat AIDS patients, competition among pharmaceutical companies drove down prices and made antiretroviral drugs more widely available. "We have seen that in countries like Cameroon, Mozambique and Kenya that as the cost of drugs comes down, governments start to talk about infrastructure, and patient access to the drugs goes up," said T'Hoen. "Regardless of problems with infrastructure, countries can't begin to deliver drugs they can't afford."

In Zimbabwe, where 2,500 people are reported to die of AIDS every week, health professionals and AIDS activists said the Geneva deal was welcome but might not be effective if other factors affecting poor countries were not addressed, such as shortages of health workers, and provision of clean water and electricity. "There is a lot involved. It just does not end at the cost of antiretroviral drugs," said Sara Page, the health promotions manager for the Southern Africa HIV/AIDS Information Dissemination Service. 
In light of all the viewpoints that the WTO had to contend with regarding TRIPS, it is amazing that the representatives of 146 nations were able to come together to unanimously agree on a document that at least takes a step toward removing the barriers that keep life-saving drugs from people in the poorest countries. Agreements such as these show that it is possible to begin to strike a balance between the needs of developed and developing countries, as well as between those of poor people and the pharmaceutical industry. WTO director-general Supachai Panitchpakdi has hailed the TRIPS agreement as proof that the organization has begun to find ways to balance humanitarian issues with trade concerns. Similar measures are needed to address the other obstacles that keep drugs from the people in the greatest need.

1. Attaran, A., and Gillespie-White, L. 2001. Do patents for antiretroviral drugs constrain access to AIDS treatment in Africa? JAMA. 286:1886-1892. 